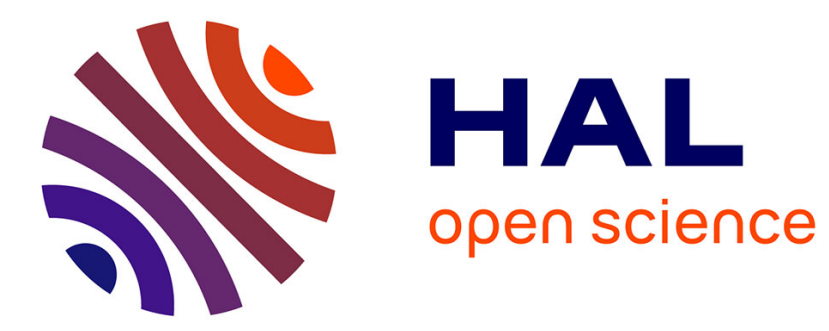

\title{
Impact of battery ageing on e-mobility energy efficiency
} Eduardo Redondo-Iglesias, Pascal Venet, Serge Pelissier

\section{To cite this version:}

Eduardo Redondo-Iglesias, Pascal Venet, Serge Pelissier. Impact of battery ageing on e-mobility energy efficiency. EVER 2017, Apr 2017, Monaco, Monaco. 6 p, 10.1109/EVER.2017.7935882. hal-01510765v3

\section{HAL Id: hal-01510765 \\ https://hal.science/hal-01510765v3}

Submitted on 21 Jun 2017

HAL is a multi-disciplinary open access archive for the deposit and dissemination of scientific research documents, whether they are published or not. The documents may come from teaching and research institutions in France or abroad, or from public or private research centers.
L'archive ouverte pluridisciplinaire HAL, est destinée au dépôt et à la diffusion de documents scientifiques de niveau recherche, publiés ou non, émanant des établissements d'enseignement et de recherche français ou étrangers, des laboratoires publics ou privés. 
REDONDO-IGLESIAS, Eduardo, VENET, Pascal, PELISSIER, Serge, 2017, Impact of battery ageing on emobility energy efficiency, 2017 Twelfth International Conference on Ecological Vehicles and Renewable Energies (EVER), MONACO, 2017-04-11, Institute of Electrical and Electronics Engineers - IEEE, $6 p$

DOI : 10.1109/EVER.2017.7935882

http://dx.doi.org/10.1109/EVER.2017.7935882

CCopyright 2017 IEEE - All rights reserved 


\title{
Impact of battery ageing on e-mobility energy efficiency
}

\author{
Eduardo REDONDO-IGLESIAS $S^{1,2, *}$ \\ Pascal VENET ${ }^{2}$ \\ Serge PELISSIER ${ }^{1}$ \\ ${ }^{1}$ Univ Lyon, IFSTTAR, AME, LTE, 69675 Bron Cedex, France \\ ${ }^{2}$ Univ Lyon, Université Lyon 1, AMPERE UMR CNRS 5005, 69622 Villeurbanne Cedex, France \\ *e-mail: eduardo.redondo@ifsttar.fr
}

\begin{abstract}
This paper focuses on energy efficiency degradation of two lithium-ion technologies, NMC (Nickel Manganese Cobalt) and LFP (Lithium Iron Phosphate), under accelerated calendar ageing tests. Results reveal the importance of considering battery ageing in the design phase of electric vehicles, not only for capacity but also for energy efficiency reasons.
\end{abstract}

Keywords-Energy efficiency; Energy storage systems; Lithium-ion batteries; Accelerated Ageing; Calendar Ageing

\section{INTRODUCTION}

Battery Electric Vehicles (BEV) are much more energy efficient than Internal Combustion Engine Vehicles (ICEV). BEV's and ICEV's powertrain efficiency are about $70 \%$ and $20 \%$ respectively but this difference can significantly decrease when considering primary energy efficiency [1]. For this reason, every element in the energy conversion chain should be optimized: from power generation and distribution to vehicle energy use.

The battery is probably the most sensitive element in the BEV powertrain system because of its cost and lifespan. Lithium-ion is nowadays the main technology for traction batteries because of its higher energy density and energy efficiency compared to previous existing technologies [2]. Lithium-ion technology has many other advantages over preceding technologies, for example: coulombic efficiency (CE) of NiMH is about 90\% [3], but in lithium-ion batteries CE is at least $99.9 \%$ [4]. Finally, memory effect exists in NiMH and lead-acid cells [5, 6] but not in lithium-ion cells. Although voltage hysteresis exists in LFP cells [7], this phenomenon does not cause a significant capacity reduction.

Ageing mechanisms are responsible of performance degradation of batteries: decrease of the amount of storable energy (capacity fade) and power availability (impedance increase). Depending on ageing path and battery composition, each ageing mechanism may act in a different magnitude. Hence, there is not always a direct correlation between impedance increase and capacity fade [8-10].

On one hand, previous works on lithium-ion ageing dealt with modelling capacity fade [11], impedance rise [8] or both: capacity and impedance degradation [12]. On the other hand, some authors dealt with energy efficiency on NiMH or lithium ion cells $[3,13,14]$ and its dependence of current rate. But energy efficiency evolution throughout battery's lifespan is not often studied.

Within SIMCAL project, a performance comparison over calendar ageing was made [15]: in that work, capacity, impedance and also average cycle energy efficiency were analyzed.

Battery energy efficiency is often considered in the design phase of vehicles, for example for battery sizing. This characteristic is age dependent: it will degrade over time like other characteristics (capacity, impedance, etc.). Energy efficiency varies over state of charge (SoC), thus the battery use should be optimized to operate in highest efficient SoC levels. Consequently, for a better consideration, energy efficiency degradation over time must be taken into account. In this work we propose to study the energy efficiency characterization over SoC and its evolution during calendar ageing tests.

\section{EXPERIMENTAL}

In the SIMCAL project, more than a hundred lithiumion cells from different manufacturers and positive electrode compositions were tested in calendar ageing [16]. The calendar ageing tests consisted in a full test matrix with three different temperatures $\left(\mathrm{T}=30,45\right.$ and $\left.60^{\circ} \mathrm{C}\right)$ and three different state-of-charge levels $(\mathrm{SoC}=30,65$ and $100 \%$ ) i.e. a full factorial design $3^{2}$ ( 2 factors, 3 levels per factor). Lithium-ion manufacturers recommend 

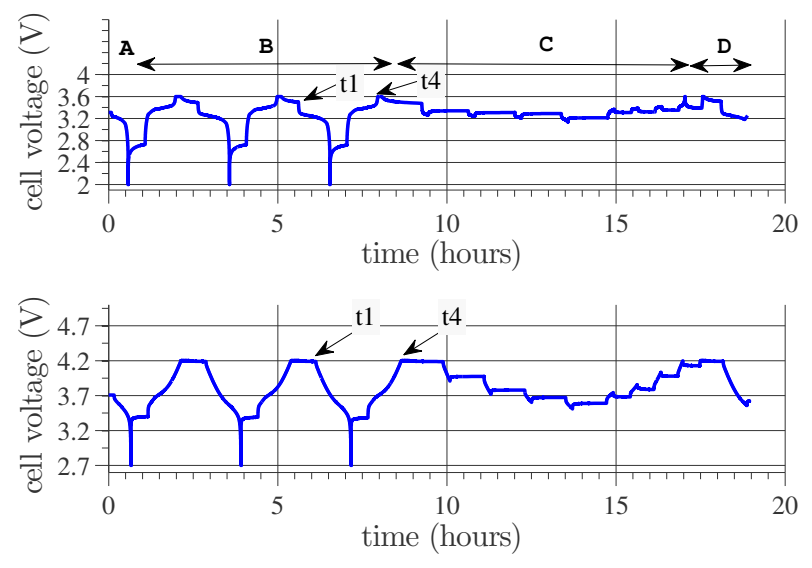

Figure 1: Voltage during first RPT for LFP (up) and NMC (bottom) cells.

not to use this technology over $60^{\circ} \mathrm{C}$, thus this is the high limit of temperature for ageing tests. Higher temperatures can induce thermal runaway even in rest conditions [17].

Three cells were tested at each test condition for each lithium-ion technology in order to improve the representativeness of results. Two technogies were tested: NMC cells are from Kokam (SLPB 70205130P, 12Ah pouch cells), whereas LFP cells are from A123 (ANR26650M1A, 2.3Ah, cylindrical cells).

The cells' characteristics were periodically measured at $25^{\circ} \mathrm{C}$ by the mean of RPT (Reference Performance Test). RPT's (figure 1) are composed in 4 phases:

(A) a full discharge to measure the remaining charge in the cell,

(B) two full charge/discharge cycles to measure the cell capacity,

(C) a partial discharge/charge cycle with cell impedance measurements at $5 \mathrm{SoC}$ levels,

(D) a full charge followed by a partial discharge to restore the $\mathrm{SoC}$ to a value in agreement with the ageing test conditions.

\section{Methodology}

Energy efficiency can be measured by several ways. Most common one consists in calculate the whole cycle efficiency after a full charge / full discharge. For example, ISO standard tests [18] attempt to characterize energy efficiency in this way.

US-DOE method [19] is based on the performance of 100 charge balanced power profiles at specified SoCs. Any variation in the $\mathrm{SoC}$ of the batteries under test enables to estimate the energy efficiency at this specified SoC. The main disadvantages of this method are the test

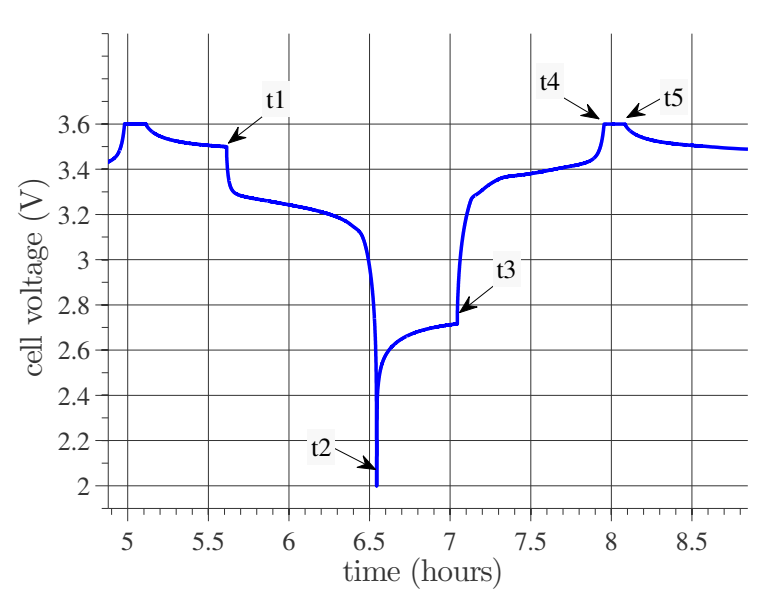

Figure 2: Zoom in last cycle (LFP cell).

duration and the difficulty to avoid excessive SoC drift during the tests.

Kang et al. [13] proposed a method to measure energy efficiency of battery cells under constant current (CC) charges or discharges. This method lies on the definition of the net energy of a cell as a function of OCV (open circuit voltage) and SoC. Firstly, OCV must be characterized by a pseudo-OCV or an incremental-OCV approach [20]. Once OCV as a function of SoC is known, net energy is easily obtained by integration of currentOCV product $(i \cdot O C V)$ whereas charge and discharge energy are obtained by integration of $i \cdot u_{\text {charge }}$ and $i \cdot u_{\text {discharge }}$ respectively. Finally, charge (discharge) energy efficiency is the relation between charge (discharge) energy and net energy [13, 14].

RPT design in SIMCAL project was originally intended for measuring capacity and impedance, not for energy efficiency. In this work we analyze energy efficiency in a similar way to [13]. Unlike Kang's method we do not attempt to separate charge and discharge efficiencies because SIMCAL RPTs do not offer a reliable measure for OCV (absence of pseudo-OCV phase).

The base equations for cell power and SoC are (1) and (2) respectively. Note that $\mathrm{SoC}$ is reported to initial capacity $\left(Q_{0}\right)$ instead current capacity $(Q)$ to be able to compare the SoC during ageing.

$$
\begin{gathered}
P(t)=u(t) i(t) \\
S o C(t)=\frac{\int i(t) d t}{Q_{0}}+S o C_{0}
\end{gathered}
$$

For each RPT, the power efficiency of last dischargecharge cycle (figure $1, t_{1}$ to $t_{4}$ ) is calculated. From $t_{1}$ 
to $t_{2}$ battery is discharged at $\mathrm{CC} 1 \mathrm{C}$, from $t_{2}$ to $t_{3}$ battery is in rest condition and from $t_{3}$ to $t_{4}$ battery is charged with CC 1C (figure 2). Obviously, full charge is not reached during $\mathrm{CC}$ charges and a subsequent $\mathrm{CV}$ (constant voltage) phase is performed from $t_{4}$ to $t_{5}$ to ensure full charging of the cell.

We will only consider CC phases for energy efficiency $\left(t_{1}\right.$ to $\left.t_{4}\right)$, there are three different periods (a),(b) and (c):

(a) for $t_{1}<t<t_{2}$ (discharge)

(b) for $t_{2}<t<t_{3}$ (rest)

(c) for $t_{3}<t<t_{4}$ (charge)

Consequently, the base equations (1) and (2) during these three periods (a),(b) and (c) become respectively (3) and (4).

$$
\begin{gathered}
P(t)= \begin{cases}-I_{\text {nom }} u(t), & \text { (a) } \\
0, & \text { (b) } \\
I_{\text {nom }} u(t), & \text { (c) }\end{cases} \\
\text { SoC }(t)=\left\{\begin{array}{l}
100\left(1-\left(t-t_{1}\right) \frac{I_{n o m}}{Q_{0}}\right), \\
0, \\
100\left(t-t_{3}\right) \frac{I_{n o m}}{Q_{0}},
\end{array}\right.
\end{gathered}
$$

As a convention in equation (4), we consider SoC $=0 \%$ during rest phase (b) independently of capacity loss $\left(Q_{L}\right)$. Note that in this equation, $\mathrm{SoC}$ is related to initial capacity $\left(Q_{0}\right)$, thus the maximum $\mathrm{SoC}$ at the end of CV charge drifts from $100 \%$ in fresh cells to $100(1-$ $\left.Q_{L} / Q_{0}\right) \%$ in aged cells.

Average energy efficiency over charge/discharge cycles is typically computed with equation (5) as in [15]. This quantity gives us an important information about energy efficiency when batteries are used over the whole SoC domain:

$$
\eta_{\text {cycle }}=\frac{\left|E_{\text {discharge }}\right|}{\left|E_{\text {charge }}\right|}=-\frac{\int_{t_{1}}^{t_{2}} P(t) d t}{\int_{t_{3}}^{t_{4}} P(t) d t}
$$

In many applications such electrical vehicles (EV) and hybrid electrical vehicles (HEV), batteries are often used in a partial SoC zone. As SoC is an important factor of battery ageing, energy efficiency characterisation as a function of SoC is necessary. This would help to determine the best SoC zone to operate in optimal conditions of energy efficiency and minimal ageing. Equation (6) expresses efficiency as a function of SoC:

$$
\eta(S o C)=\frac{\left|P_{\text {discharge }}(S o C)\right|}{\left|P_{\text {charge }}(S o C)\right|}
$$

We need to express the power as a function of SoC. From equation (4), SoC relation with time $(\operatorname{SoC}(t))$ is linear during $\mathrm{CC}$ charges and discharges. A change of variable is easily operable in (3), giving the expression (7):

$$
P(S o C)= \begin{cases}-I_{\text {nom }} u(S o C), & \text { (a) } \\ 0, & \text { (b) } \\ I_{\text {nom }} u(S o C), & \text { (c) }\end{cases}
$$

By substituting (7) in (6), we obtain the expression of power efficiency as a function of $\mathrm{SoC}$ at a given current rate (8):

$$
\eta(S o C)=\frac{u_{\text {discharge }}(S o C)}{u_{\text {charge }}(S o C)}
$$

Equation (8) is an approximation to power efficiency as the ratio between $u_{\text {discharge }}$ and $u_{\text {charge }}$. This equation is valid for applications such battery pack dimensioning or battery technology benchmarking. For a fine estimation of energy losses, other models are more suitable like, for example equivalent circuit models.

\section{RESULTS}

In this work we have considered two different lithiumion technologies: NMC and LFP. NMC batteries have several advantages compared to LFP, mainly they have a higher energy density (125 and $106 \mathrm{kWh} / \mathrm{kg}$ respectively for the tested cells). However, LFP batteries are good candidates for long life and high current rate applications.

Figure 3 shows charge and discharge curves of these two cell types and efficiency calculated by eq. (8), obtained from the first RPT. Efficiency of NMC cells is monotonically increasing with SoC, in contrary LFP cells' efficiency decreases rapidly in the extremities (0 and $100 \%$ SoC). LFP efficiency has also a local minimum at $30 \% \mathrm{SoC}$.

Figure 4(a) shows the energy efficiency versus $\mathrm{SoC}$ for a NMC cell during ageing at $60^{\circ} \mathrm{C}$ and $100 \%$ SoC. At the begining of the ageing test mean efficiency was $96 \%$, but after 190 days the mean efficiency went down $87 \%$ and the capacity loss reached $37 \%$.

Ageing tests were carried on LFP cells during 378 days, end of life was achieved in 337 days (figure 5). Despite of capacity loss, efficiency was almost constant during the ageing tests: initial efficiency was $95 \%$ and decreased only $1 \%$ (to $94 \%$ ) at end of life. 


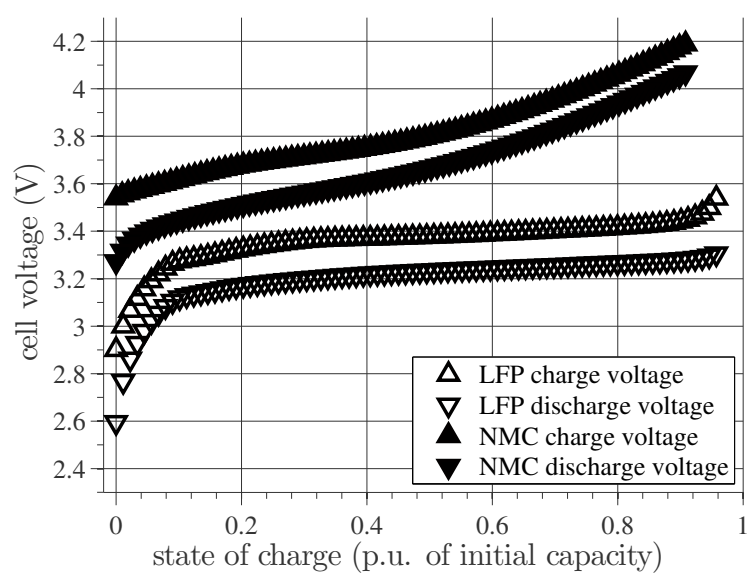

(a)

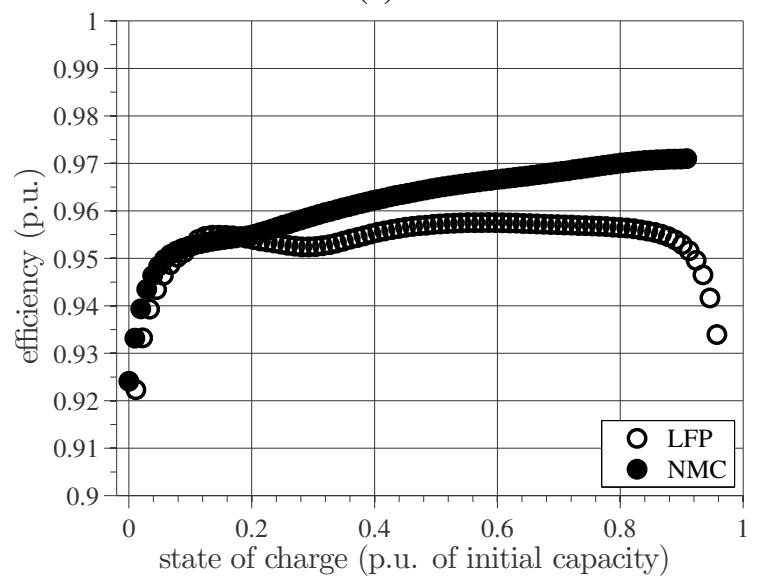

(b)

Figure 3: Charge and discharge voltages (a) and efficiency (b) of fresh cells.

\section{DISCUSSION}

Results in the previous section indicate efficiency for different values of SoC at various ageing status. In real conditions of use batteries are often discharged by a constant value of Amp-hours $(\Delta Q)$, for example a daily trip for an electric vehicle. Computing efficiency of a battery during its life and for a constant $\Delta \mathrm{Q}$ use, drives to consider a non constant SoC during the operation. $\Delta \mathrm{Q}$ could be calculated in $\%$ of the initial capacity $Q_{0}$. Then a $\Delta$ Q60 corresponds to SoC40 at the beginning of life, but corresponds to SoC10 after $30 \%$ of capacity fade.

Figures 4(b) and 5(b) show the evolution of the efficiency versus capacity loss for various constant $\Delta \mathrm{Q}$ applications. The average efficiency evolution is also plotted.

For the NMC cell, efficiency at $\Delta \mathrm{Q} 20, \Delta \mathrm{Q} 40$ and $\Delta \mathrm{Q} 60$ decrease at the same rate than average efficiency until $30 \%$ of capacity loss (figure 4(b)). From 30\% of capacity loss, efficiency rate of decrease at $\Delta \mathrm{Q} 60$ accelerates because at this ageing state $\Delta \mathrm{Q} 60$ is equivalent to

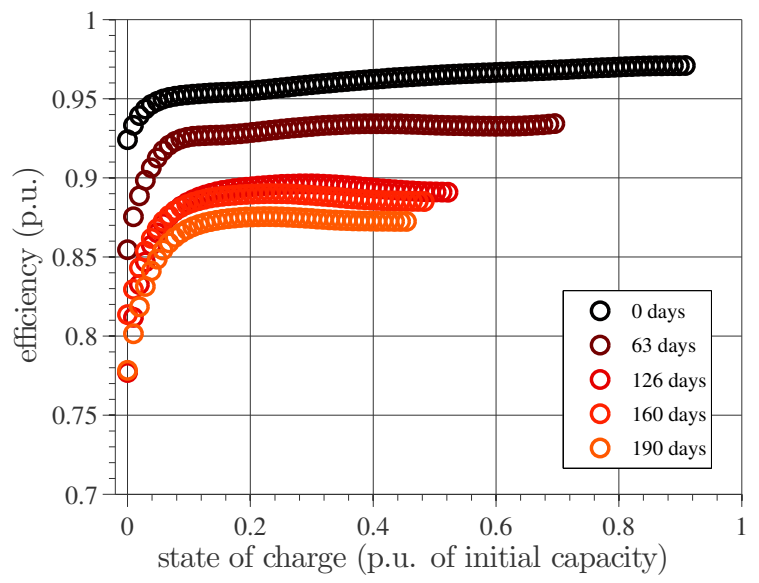

(a) vs. SoC

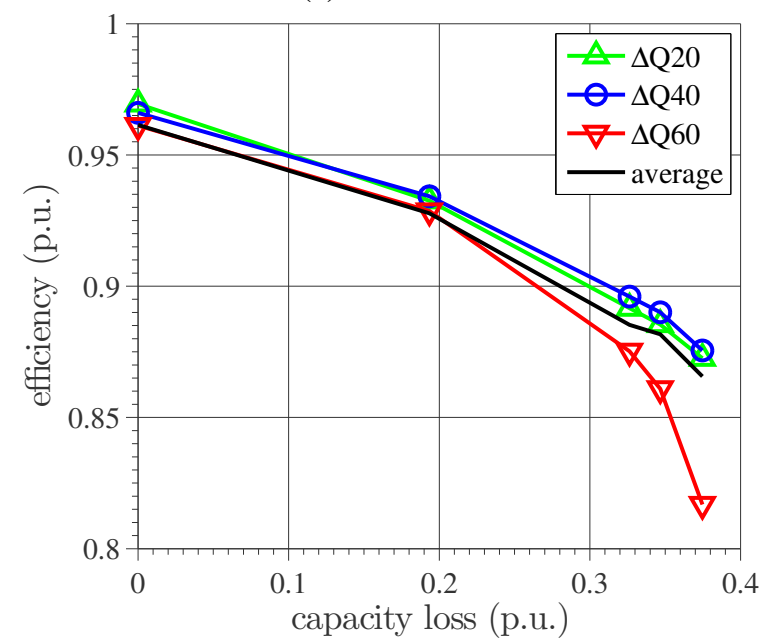

(b) vs. capacity loss

Figure 4: Energy efficiency degradation of NMC cells (ageing conditions: $60^{\circ} \mathrm{C}, 100 \% \mathrm{SoC}$ ).

a very low SoC (less than $10 \%$ ).

LFP efficiency evolution during ageing has a very characteristic behaviour: at the beginning of life, despite of the cell ageing, efficiency at lower $\Delta$ Qs seems to increase instead to decrease (figure 5(b), $\Delta$ Q20 and $\Delta \mathrm{Q} 40)$.

$\Delta$ Q60 efficiency decreases at a quite constant rate until $18 \%$ of capacity loss, then efficiency stops decreasing from 18 to $25 \%$ of $Q_{L}$. Finally the rate of decrease accelerates at end of life for the same reason than in NMC.

$\Delta$ Q40's efficiency decreases rapidly from $Q_{L}=15$ to $29 \%$ and then efficiency seems to stop falling and becomes similar to $\Delta \mathrm{Q} 20$ in the last point.

The accelerations and decelerations in the decreasing rate lie on the particular characteristic of efficiency over SoC. Figure 6 is a zoom of figure 5(a) where constant $\Delta \mathrm{Q}$ paths are superposed. This figure enables to better 


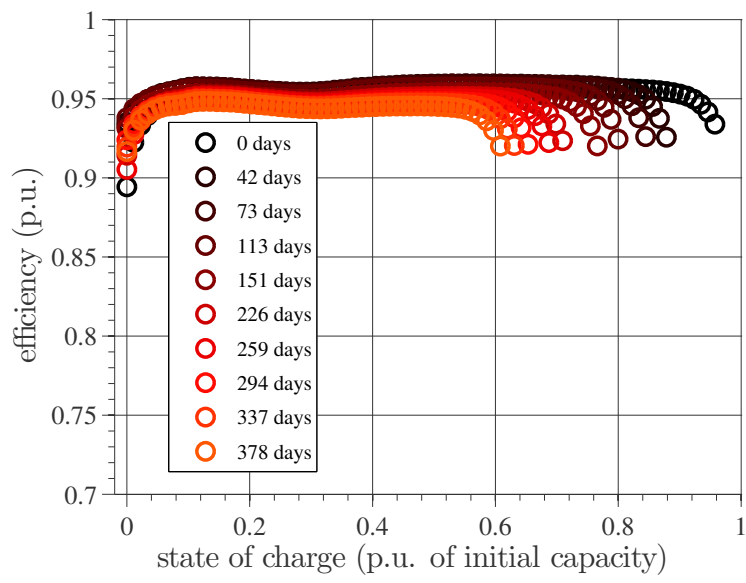

(a) vs. SoC

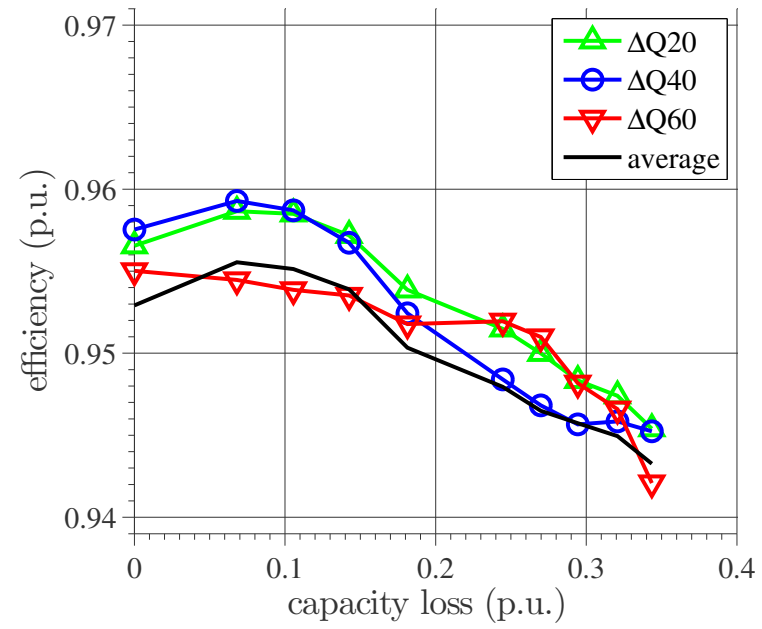

(b) vs. capacity loss

Figure 5: Energy efficiency degradation of LFP cells (ageing conditions: $60^{\circ} \mathrm{C}, 100 \% \mathrm{SoC}$ ).

understand the variation of efficiency in figure 5(b).

In fresh cells, efficiency has a 'hill' at SoC15, a 'valley' at about SoC30 and a 'plateau' from SoC40 to SoC90. During cell ageing, the local maximum ('hill') and the local minimum ('valley') seem to be almost immobile but the plateau contracts.

Because of the SoC drift of constant $\Delta \mathrm{Q}$ paths, constant $\Delta \mathrm{Q}$ efficiencies 'fall' into this valley successively (figure 6). $\Delta \mathrm{Q} 60$ starts at $\mathrm{SoC} 40$ and reaches the local minimum in 73 days $\left(Q_{L}=10 \%\right)$, then it moves up to the local maximum until $Q_{L}=25 \%$. From $Q_{L}=18$ to $25 \% \Delta \mathrm{Q} 60$ efficiency stops decreasing because in one side SoC drifts from the 'valley' to the 'hill' and in the other side the whole efficiency curve moves down. Finally, from $Q_{L}=25 \%, \Delta \mathrm{Q} 60$ efficiency decreases rapidly because both, the whole efficiency curve moves down and the SoC drifts from the 'hill' to SoC0.

For $\Delta \mathrm{Q} 40$ the local minimum is reached in 294 days (capacity loss $=29 \%$ ), then the efficiency stops falling

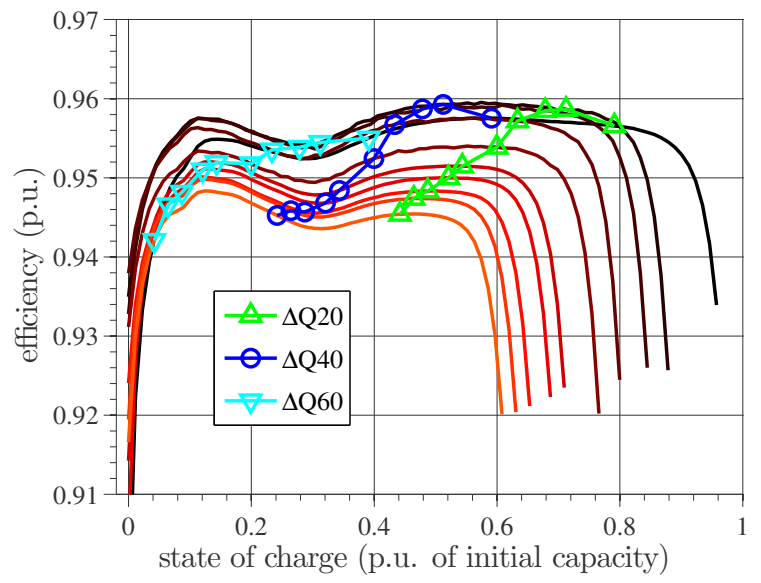

Figure 6: Zoom on energy efficiency degradation. Color code is the same than in figure 5(a): from black to orange lines represent efficiency $\mathrm{vS}$. SoC at each ageing state. Constant $\Delta \mathrm{Q}$ paths are superposed $(\Delta \mathrm{Q} 20, \Delta \mathrm{Q} 40$, $\Delta \mathrm{Q} 60)$.

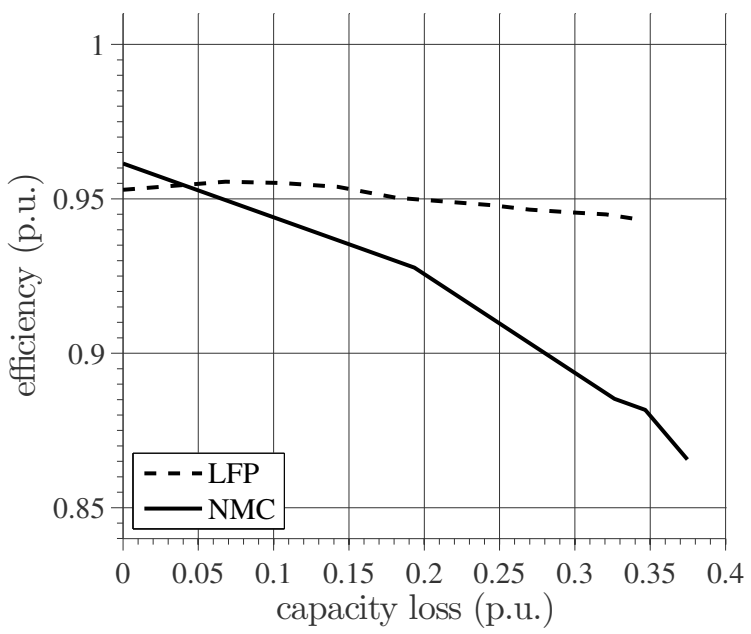

Figure 7: Mean energy efficiency vs. capacity loss.

and becomes similar to $\Delta \mathrm{Q} 20$ in the last point. At this point, $\Delta$ Q40 path is leaving the valley while $\Delta$ Q20 path is reaching the valley.

When comparing LFP and NMC cells (figure 7), we realise that NMC's efficiency is higher than LFP's one but only in fresh batteries. Efficiency rate of decrease is much faster in NMC than in LFP. At end of life, energy efficiency is about $94 \%$ in LFP but less than $90 \%$ in NMC.

In some applications such VEH, battery is used in a relatively narrow window of SoC. The SoC window may be chosen to optimise energy efficency or lifetime. In NMC cells, the best efficiency is achieved at the highest SoC levels that induce a higher degradation: a compromise must be found between efficiency and 
lifetime.

On the other side, in LFP cells highest SoC levels (>90\%) must be avoided for both efficiency and lifetime reasons. This can be seen as an advantage of LFP over NMC: the best choice of SoC minimises both degradation and energy losses.

In conclusion, fresh cell characteristics such energy density or efficiency give us important but insufficient information and can lead to wrong decisions. When evaluating cell ageing, characteristics may degrade at different rates. In this study case, NMC cells have a faster degradation in terms of energy (capacity loss) and efficiency than LFP cells. Efficiency of LFP cells does not decrease significantly: from $95 \%$ to $94 \%$ throughout the lifetime.

\section{CONCLUSIONS}

In one hand, energy efficiency of batteries is usually considered in the design phase of electric vehicles. On the other hand, capacity fade (sometimes also impedance rise) throughout the lifetime is often evaluated by the means of accelerated ageing tests. Nevertheless, energy efficiency evolution over lifespan is not often considered.

In this work we intended to evaluate energy efficiency degradation in accelerated calendar ageing for two lithium-ion technologies at $60^{\circ} \mathrm{C}$ and $100 \%$ SoC. SIMCAL project which was not originally designed for measuring energy efficiency but energy efficiency can be calculated as the ratio between voltage during constant current charges and discharges.

Constant current phases of full charge/discharge cycles allowed us to build the characteristic curves of power efficiency over SoC at each state of ageing for two lithium-ion technologies: NMC and LFP. Characteristic curves reveal the best $\mathrm{SoC}$ regions to operate in terms of efficiency. LFP showed a particular behaviour with a local minimum of efficiency at SoC30.

Energy efficiency analysis within battery ageing offers a more global scope than capacity/impedance modelling. Further work will consist in completely characterise energy efficiency degradation under different ageing conditions. After completely characterising, an energy efficiency ageing model could be developed. This work can represent a decisional tool to help in the design process of electric vehicles.

\section{AKNOWLEDGEMENT}

This work uses data from SIMCAL project. SIMCAL project (2009-2012) was funded by the French National Research Agency (ANR). SIMCAL partners are
CEA, EDF, EIGSI, IFPEN, IFSTTAR, IMS, LEC, LMSImagine, LRCS, PSA, RENAULT, SAFT, and VALEO.

\section{REFERENCES}

[1] M. Åhman, Energy, vol. 26, no. 11, pp. 973 - 989, 2001.

[2] R. Moshtev and B. Johnson, Journal of Power Sources, vol. 91, no. 2, pp. 86 - 91, 2000.

[3] W. H. Zhu, Y. Zhu, Z. Davis, et al., Applied Energy, vol. 106, pp. 307 - 313, 2013.

[4] Y. Zheng, M. Ouyang, L. Lu, et al., Journal of Power Sources, vol. 289, pp. 81 - 90, 2015.

[5] T. Reddy, Linden's handbook of batteries. New York: McGraw-Hill, 2011.

[6] R. F. Nelson and D. M. Wisdom, Journal of Power Sources, vol. 33, no. 1, pp. 165 - 185, 1991.

[7] M. A. Roscher, J. Vetter, and D. U. Sauer, Journal of Power Sources, vol. 191, no. 2, pp. 582 - 590, 2009.

[8] I. Bloom, B. Cole, J. Sohn, et al., Journal of Power Sources, vol. 101, no. 2, pp. 238 - 247, 2001.

[9] J. Vetter, P. Novák, M. Wagner, et al., Journal of Power Sources, vol. 147, no. 1 - 2, pp. $269-281$, 2005.

[10] K. L. Gering, S. V. Sazhin, D. K. Jamison, et al., Journal of Power Sources, vol. 196, no. 7, pp. 3395 - 3403, 2011.

[11] S. Grolleau, A. Delaille, H. Gualous, et al., Journal of Power Sources, vol. 255, pp. 450-458, 2014.

[12] M. Ecker, N. Nieto, S. Käbitz, et al., Journal of Power Sources, vol. 248, pp. 839 - 851, 2014.

[13] J. Kang, F. Yan, P. Zhang, et al., Journal of Power Sources, vol. 206, pp. 310 - 314, 2012.

[14] J. Kang, F. Yan, P. Zhang, et al., Energy, vol. 70, pp. $618-625,2014$.

[15] A. Eddahech, O. Briat, and J.-M. Vinassa, Energy, vol. 84, pp. $542-550,2015$.

[16] A. Delaille, S. Grolleau, F. Duclaud, et al. in ECS Meeting Abstracts, no. 14, (San Francisco), p. 1191, The Electrochemical Society, Oct. 2013.

[17] J. Jousse, E. Lemaire, N. Ginot, et al. in Industrial Electronics Society, IECON 2013 - 39th Annual Conference of the IEEE, pp. 1530-1535, Nov 2013.

[18] ISO12405-2:2012, Electrically propelled road vehicles - Test specification for lithium-ion traction battery packs and systems - Part 2: High-energy applications. 2012.

[19] PNGV, Battery Test Manual. U.S. Department of Energy, DOE/ID-10597 rev3. Feb. 2001.

[20] M. Petzl and M. Danzer, Energy Conversion, IEEE Transactions on, vol. 28, pp. 675-681, Sept 2013. 